\title{
The Mechanical and Electronic Properties of Ternary Rare-Earth Hexaboride $\mathrm{La}_{\mathrm{x}} \mathrm{Nd}_{8-\mathrm{x}} \mathrm{B}_{6}$ $(x=0,1,7,8)$ Materials
}

\section{Cengiz Bozada}

Department of Metallurgical and Material Science Engineering, Faculty of Engineering, Gaziantep University, Gaziantep, Turkey Email: b.ankara@yandex.com

How to cite this paper: Bozada, C. (2022) The Mechanical and Electronic Properties of Ternary Rare-Earth Hexaboride $\mathrm{Lax}_{\mathrm{N}} \mathrm{Nd}_{8 \mathrm{x}} \mathrm{B}_{6}$ $(\mathrm{x}=0,1,7,8)$ Materials. Modeling and $\mathrm{Nu}$ merical Simulation of Material Science, 12, $1-11$.

https://doi.org/10.4236/mnsms.2022.121001

Received: January 1, 2022

Accepted: January 27, 2022

Published: January 30, 2022

Copyright $\odot 2022$ by author(s) and Scientific Research Publishing Inc. This work is licensed under the Creative Commons Attribution International License (CC BY 4.0).

http://creativecommons.org/licenses/by/4.0/

\begin{abstract}
We have carried out density functional theory to study the lattice constants and electronic properties of $\mathrm{LaB}_{6}, \mathrm{NdB}_{6}$, Nd-doped $\mathrm{LaB}_{6}$, and La-doped $\mathrm{NdB}_{6}$. The lattice constant, intra-octahedral bond, inter-octahedral boron bond, and positional parameter ( $\mathrm{z}$ ) were calculated for $\mathrm{LaB}_{6}, \mathrm{La}_{7} \mathrm{Nd}_{1} \mathrm{~B}_{6}, \mathrm{La}_{1} \mathrm{Nd}_{7} \mathrm{~B}_{6}$, and $\mathrm{NdB}_{6}$. Our results show that the doped $\mathrm{Nd}$ increases the lattice constant of $\mathrm{La}_{7} \mathrm{Nd}_{1} \mathrm{~B}_{6}$. Likewise, La-doping leads to an increase in the lattice constant of the $\mathrm{La}_{1} \mathrm{Nd}_{7} \mathrm{~B}_{6}$. The PDOSs of $\mathrm{LaB}_{6}, \mathrm{~B}$ of $\mathrm{LaB}_{6}, \mathrm{La}_{7} \mathrm{Nd}_{1} \mathrm{~B}_{6}, \mathrm{~B}$ of $\mathrm{La}_{7} \mathrm{Nd}_{1} \mathrm{~B}_{6}$, $\mathrm{La}_{1} \mathrm{Nd}_{7} \mathrm{~B}_{6}, \mathrm{~B}$ of $\mathrm{La}_{1} \mathrm{Nd}_{7} \mathrm{~B}_{6}, \mathrm{NdB}_{6}$, and $\mathrm{B}$ of $\mathrm{NdB}_{6}$ were calculated. La d-electron bands cross the Fermi energy, showing classical conductor behavior. The charge density results indicate that light and dark colors show high and low-intensity zones, respectively. $\mathrm{La}_{1} \mathrm{Nd}_{7} \mathrm{~B}_{6}$ has a low-density region and $\mathrm{LaB}_{6}$ has a high-density region. The $\mathrm{LaB}_{6}$ midpoint has strong charge density peaks. Weak peaks are also observed for $\mathrm{La}_{1} \mathrm{Nd}_{7} \mathrm{~B}_{6}$. Thus, ternary $\mathrm{REB}_{6}$ has good potential for many applications. This article reports an investigation of the electronic features and structural parameters of binary and ternary hexaborides.
\end{abstract}

\section{Keywords}

Rare-Earth Hexaboride, Lattice Constant, PDOS, Charge Density

\section{Introduction}

Rare-earth hexaborides $\left(\mathrm{REB}_{6}\right)$ are commonly used in various high-energy optical devices and field electron emitter systems because of their superior properties such as high chemical stability, high melting point, high mechanical strength, high brightness, low work function, low volatility, conductibility, small visual dimensions and long lifetimes [1]. $\mathrm{REB}_{6}$ is commonly used as cathode material. 
$\mathrm{REB}_{6}$ has a cubic CsCl-type structure with a space group of Pm-3m symmetry, in which a rare-earth (RE) ion occupies the $C s$ site, and the $B_{6}$ octahedron is located on the $\mathrm{Cl}$ site. $\mathrm{REB}_{6}$ compounds include $\mathrm{LaB}_{6}, \mathrm{CeB}_{6}, \mathrm{PrB}_{6}, \mathrm{NdB}_{6}, \mathrm{PmB}_{6}, \mathrm{SmB}_{6}$, $\mathrm{EuB}_{6}, \mathrm{GdB}_{6}, \mathrm{TbB}_{6}, \mathrm{DyB}_{6}, \mathrm{HoB}_{6}, \mathrm{ErB}_{6}, \mathrm{TmB}_{6}, \mathrm{YbB}_{6}, \mathrm{LuB}_{6}, \mathrm{ScB}_{6}$ and $\mathrm{YB}_{6} . \mathrm{LaB}_{6}$ has low volatility, $\mathrm{CeB}_{6}$ indicates a typical dense Kondo behavior, $\mathrm{PrB}_{6}$ shows high density, $\mathrm{NdB}_{6}$ has low magnification, $\mathrm{SmB}_{6}$ is a typical valence semiconductor and $\mathrm{GdB}_{6}$ has the lowest work function among $\mathrm{REB}_{6}$ compounds [2].

The electronic structures of the doped and binary $\mathrm{REB}_{6}$ were calculated using density functional theory (DFT). The position of the Fermi energy level and DOS were adjusted by doping with $\mathrm{REB}_{6}$ to improve the electron emission characteristics. The high-density d-orbital electrons play a crucial role in considerably decreasing the work function of $\mathrm{REB}_{6}$ and contributing to the electronic states of electron emission near the Fermi level. This ensures excellent emission characteristics [3]. The second-order elastic constants (SOECs) and third-order elastic constants (TOECs) of $\mathrm{LaB}_{6}$ and $\mathrm{CeB}_{6}$ were studied by first-principles calculations. The effect of increased pressure on the elastic anisotropy, mechanical characteristics and structural stability of $\mathrm{LaB}_{6}$ and $\mathrm{CeB}_{6}$ has attracted considerable attention. When the pressure increases, the mechanical stability decreases and the ductility and anisotropy increase [1]. Lanthanum hexaborides $\left(\mathrm{LaB}_{6}\right)$ are superb thermionic and field electron emission cathode materials in the field of electron emission. $\mathrm{LaB}_{6}$ has several applications in high-power electronics owing to its long lifetime and high luminosity. $\mathrm{LaB}_{6}$ attracts attention by its low work function between 2.6 and $2.8 \mathrm{eV}$, its high melting point of $2715^{\circ} \mathrm{C}$, and its stable chemical and physical characteristics. Compared to polycrystalline and single-crystal applications of $\mathrm{LaB}_{6}$, it has better potential for single-crystal applications [4]. $\mathrm{LaB}_{6}$ works well as a thermal-field emitter. It is easily degradable and stable in air. $\mathrm{LaB}_{6}$ was reactive at $2715^{\circ} \mathrm{C} . \mathrm{LaB}_{6}$ is a violet-colored metal and its electron conductivity is approximately $1 / 5$ that of copper [5]. Lu et al. [6] successfully fabricated $\mathrm{LaB}_{6}$ nanocubes with an average dimension of $94.7 \mathrm{~nm}$ using a lowtemperature molten salt technique at $800^{\circ} \mathrm{C} . \mathrm{LaB}_{6}$ nanocubes exhibited high near-infrared (NIR) adsorption. As mentioned in [7], $\mathrm{LaB}_{6}$ nanocrystalline preparation routes include many synthesis routes, such as the floating zone method, aluminum flux, molten salt, high-temperature reaction, chemical vapor deposition (CVD), direct solid-phase reaction and carbothermal reduction. It is because of its wonderful characteristics that $\mathrm{LaB}_{6}$ is commonly used in some electrical devices, including free-electron laser, thermionic electron cathode, electron microscope, vacuum, and electron beam welder [8].

Neodymium hexaboride $\left(\mathrm{NdB}_{6}\right)$ is black solid with good chemical stability, magnetic properties, electrical conductivity, and thermal conductivity characteristic. $\mathrm{NdB}_{6}$ is insoluble in hydrofluoric acid (HF) and hydrochloric acids $(\mathrm{HCl})$. However, it can be dissolved in molten alkali, sulfuric acid $\left(\mathrm{H}_{2} \mathrm{SO}_{4}\right)$ and nitric acid $\left(\mathrm{HNO}_{3}\right)$. In addition, it exhibits very high antioxidant capability [9]. $\mathrm{NdB}_{6}$ crystallizes in a CsCl-type structure with a space group of Pm-3m symmetry, where the neodymium $(\mathrm{Nd})$ occupies the $\mathrm{Cs}$ site and octahedral $\mathrm{B}_{6}$ molecules are 
located at the $\mathrm{Cl}$ site. $\mathrm{NdB}_{6}$ has a low work function $(1.6 \mathrm{eV})[10] . \mathrm{NdB}_{6}$ are an efficient field-emission cathode material. These excellent properties make $\mathrm{NdB}_{6}$ nanomaterials promising materials for use in vacuum electronic devices [11]. Thus, $\mathrm{NdB}_{6}$ is antiferromagnetical at $\mathrm{T}_{\mathrm{N}}=7.74 \mathrm{~K}$ [12]. Ding et al. [13] successfully synthesized $\mathrm{NdB}_{6}$ nanowires (NWs) by a self-catalyst method. Nanowires with diameters of approximately $80 \mathrm{~nm}$ and lengths spanning several micrometers have monocrystalline structures. $\mathrm{Xu}$ et al. [14] successfully produced $\mathrm{NdB}_{6}$ nanostructures using a free-CVD process. The $\mathrm{NdB}_{6}$ nanostructures exhibited a good stability. The effect of temperature on $\mathrm{NdB}_{6}$ is important. When the temperature was increased, the turn-on and threshold electric fields decreased. The work function of $\mathrm{NdB}_{6}$ nanostructures is considerably decreased as the temperature increases, leading to much enhanced field emission characteristics.

Tsuji et al. [15], studied the magnetoresistance, magnetization and specific heat of $\mathrm{Nd}_{\mathrm{x}} \mathrm{La}_{1-\mathrm{x}} \mathrm{B}_{6}(\mathrm{x}=0.9,0.8,0.7,0)$ by a FZM method. The magnetoresistance, magnetization and specific heat are affected by temperature. As the temperature increased the others increase. Chaolong et al. [16] successfully investigated $\mathrm{Nd}_{\mathrm{x}} \mathrm{La}_{1-\mathrm{x}} \mathrm{B}_{6}$ bulks using spark plasma sintering (SPS) method. The work function of $\mathrm{Nd}_{\mathrm{x}} \mathrm{La}_{1-\mathrm{x}} \mathrm{B}_{6}$ was $2.72 \mathrm{eV}$. The $\mathrm{Nd}$ content enhanced thermionic emission characteristic and decreased the work function.

Li et al. [17] fabricated successfully high-quality, uniform $\operatorname{La}_{x} \mathrm{Nd}_{1-\mathrm{x}} \mathrm{B}_{6}$ nanowires by catalyst-free CVD technique. $\mathrm{La}_{\mathrm{x}} \mathrm{Nd}_{1-\mathrm{x}} \mathrm{B}_{6}$ nanowires exhibit a superb field emission performance. Nanowires are used in optoelectronic devices such as nanoelectronic building blocks and flat panel displays.

\section{Materials and Methods}

$\mathrm{Ab}$ initio material modelling based on DFT was performed quantum espresso software (QE) packages based on modelling the material at nanoscales or on an atomic scale [18]. First-principles calculations were performed using the VASP. [19]. The projector augmented wave (PAW) method and the functional form of the generalized gradient approximation (GGA) of Perdew-Burke-Ernzerhof (PBE) were preferred for exchange. The kinetic energy cut-off of the plane-wave basis set was $500 \mathrm{Ry}$. The Brillouin zone integration was performed at $3 \times 3 \times 3 \mathrm{k}$ mesh points using methfessel-paxton smearing with a width of $0.02 \mathrm{Ry}$. A $\mathrm{k}$-mesh $3 \times 3 \times 3$ was used in the brillouin zone integration with Methfessel-Paxton smearing width of $0.02 \mathrm{Ry}$. Both $\mathrm{LaB}_{6}$ and $\mathrm{NdB}_{6}$ have cubic CsCl-type structures with a space group of Pm-3m symmetry [20].

\section{Results and Discussion}

The bulk unit cell of $\mathrm{REB}_{6}$ is simple cubic and is found in the symmetry of the space group $\mathrm{Pm}-3 \mathrm{~m}$. The lattice of $\mathrm{NdB}_{6}$ can be entirely defined using merely the lattice constant, a, and the positional parameter, $z$, as indicated in Figure 1. The lattice constant, a was 1 , intra-octahedral boron bond was 2 , and inter-octahedral boron bond was 3 . 


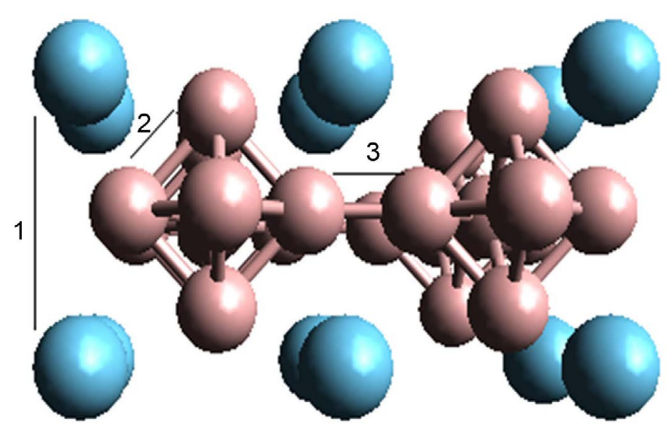

Figure 1. $\mathrm{NdB}_{6}$ structures with showing relevant bond lengths. $\mathrm{NdB}_{6}$ contains $\mathrm{Nd}$ (blue) and $\mathrm{B}$ atoms (purple) forming an octahedral structure.

Table 1 lists the positional parameters of the given $\mathrm{REB}_{6}$. The lattice constant of $\mathrm{LaB}_{6}$ (Pm-3m space group) was calculated as a value of $4.157 \AA$. This was consistent with the experimental consequences indicated in Table 1. Furthermore, parameters 2 and 3 were 1.766 and $1.660 \AA$, respectively, with a boron positional parameter of approximately $\mathrm{z}=0.226 \AA$. Chen et al. [28] conducted a study on the structural refinement and thermal expansion of hexaborides. In this study, based on the X-ray powder diffraction technique, the intra-octahedral and inter-octahedral boron-boron distances were calculated as 1.766 and $1.659 \AA$, respectively. Xiao et al. investigated the optical features of $\mathrm{LaB}_{6}$ using first-principles DFT calculations. They calculated the $\mathrm{LaB}_{6}$ parameter to be $4.154 \AA$ [33]. Hasan et al. [34] synthesized $\mathrm{LaB}_{6}$ via carbothermal reduction. The calculated value of the lattice parameter was 4.157 A. Furthermore, other experimental studies [35], [36] are consistent with those of presidential study. Mackinnon et al. [37] calculated the lattice constant of $\mathrm{LaB}_{6}$ using DFT calculations. The calculated boron parameter (z) was $0.225 \AA$.

The doping of $\mathrm{Nd}$ instead of one La atom led to a slight increase in the lattice constant to $0.502 \AA$. In addition, 2 and 3 parameters were found to be 1.857 and $1.801 \AA$, respectively, which indicates an increase in these parameters while the $\mathrm{z}$ parameter remains nearly the same as that of $\mathrm{LaB}_{6}$. In a study related to $\mathrm{La}_{\mathrm{x}} \mathrm{Gd}_{1-\mathrm{x}} \mathrm{Bd}_{6}$ synthesized by the SPS technique, the doping of $\mathrm{Gd}$ into $\mathrm{LaB}_{6}$ strengthened the lattice parameters of the structure [38]. In a similar study, Chao et al. [39] fabricated $\mathrm{La}_{7} \mathrm{Sm}_{1} \mathrm{~B}_{6}$ by solid-state technique. Sm doping led to a decrease in the $\mathrm{La}_{7} \mathrm{Sm}_{1} \mathrm{~B}_{6}$ lattice.

The 1, 2, 3 and $\mathrm{z}$ parameters; 1 of $\mathrm{La}_{1} \mathrm{Nd}_{7} \mathrm{~B}_{6}$ were found as $4.449,1.812,1.801$, and $0.223 \AA$ respectively. Compared to $\mathrm{LaB}_{6}$, the ratio of $\mathrm{Nd} / \mathrm{La}$ increased in parameters 12 , and 3 but the parameter $\mathrm{z}$ didn't change considerably. On the other hand, Li et al. [17] conducted a study of single-crystal $\mathrm{La}_{x} \mathrm{Nd}_{1-\mathrm{x}} \mathrm{B}_{6}$ nanowires to investigate the field emission performance and characterization. In this study, when $\mathrm{Nd}$-doped into $\mathrm{LaB}_{6}$, the lattice parameter of $\mathrm{La}_{x} \mathrm{Nd}_{1-x} \mathrm{~B}_{6}$ was decreased. In a similar study, Chao et al. [39] produced $\mathrm{La}_{x} \mathrm{Sm}_{1-x} \mathrm{~B}_{6}$ by solid-state reaction. They employed DFT to describe the characteristic of Sm-doped $\mathrm{LaB}_{6}$. They obtained the lattice parameters of $\mathrm{La}_{0.2} \mathrm{Sm}_{0.8} \mathrm{~B}_{6}$ and $\mathrm{La}_{0.4} \mathrm{Sm}_{0.6} \mathrm{~B}_{6}$ as 4.123 and 
Table 1. The lattice constant (1), intra-octahedral boron bond (2), inter-octahedral boron bond (3), and positional parameter ( $\mathrm{z}$ ) of REB6. $z=3 / 2 \times 1$.

\begin{tabular}{|c|c|c|c|c|c|}
\hline & & $1(\AA)$ & $2(\AA)$ & $3(\AA)$ & $\mathbf{z}(\AA)$ \\
\hline \multirow[b]{2}{*}{$\mathrm{LaB}_{6}$} & Present study & 4.157 & 1.766 & 1.660 & 0.226 \\
\hline & Previous results & $\begin{array}{c}4.154[4], 4.15[8], 4.156[21], 4.145[22], 4.156[23] \\
4.155[24], 4.155[25], 4.151[7], 4.158[26], 4.176[27]\end{array}$ & $1.766[28]$ & $1.659[28]$ & \\
\hline \multirow{2}{*}{$\mathrm{La}_{7} \mathrm{Nd}_{1} \mathrm{~B}_{6}$} & Present results & 4.267 & 1.857 & 1.801 & 0.227 \\
\hline & Previous results & & & & \\
\hline \multirow{2}{*}{$\mathrm{La}_{1} \mathrm{Nd}_{7} \mathrm{~B}_{6}$} & Present results & 4.449 & 1.812 & 1.801 & 0.223 \\
\hline & Previous results & & & & \\
\hline \multirow[b]{2}{*}{$\mathrm{NdB}_{6}$} & Present results & 4.118 & 1.750 & 1.643 & 0.227 \\
\hline & Previous results & $\begin{array}{c}4.125[29], 4.132[10], 4.12[30], \\
4.1[14], 4.157[27], 4.126[31], 4.128[32]\end{array}$ & & & \\
\hline
\end{tabular}

4.128, respectively. Their results showed that doping $\mathrm{LaB}_{6}$ with $\mathrm{Sm}$ decreases the lattice parameter of $\mathrm{La}_{x} \mathrm{Sm}_{1-x} \mathrm{~B}_{6}$. When the La content was doped into $\mathrm{BaB}_{6}$, the calculated value of the lattice constant of $\mathrm{La}_{1} \mathrm{Ba}_{7} \mathrm{~B}_{6}$ was increased [40]. Luo et al. [41] studied $\mathrm{La}_{1} \mathrm{Ca}_{7} \mathrm{~B}_{6}$ by first-principles calculations. $\mathrm{Ca}$ doping provides increases in the lattice strength of $\mathrm{La}_{1} \mathrm{Ca}_{7} \mathrm{~B}_{6}$.

The lattice constant of $\mathrm{NdB}_{6}$ was calculated as a value of 4.118. Ali et al. [12] studied the thermoelectric power of $\mathrm{NdB}_{6}$ by using the floating zone method. They measured the lattice constant was $4.126 \AA$ A. In other studies, Ping et al. [42] conducted a study of $\mathrm{NdB}_{6}$ by using the first principle method. The lattice parameter of $\mathrm{NdB}_{6}$ was calculated as $4.069 \AA$. Sandeep et al. [35] calculated the lattice parameter of $\mathrm{NdB}_{6}(4.157 \AA)$ using the full-potential linearized augmented plane wave (FP-LAPW) technique. Furthermore, parameters 2 and 3 were found to be 1.750 and $1.643 \AA$, respectively, and the z parameter was $1.643 \AA$. Mackinnon et al. [37] determined the $\mathrm{z}$ parameter as $0.226 \AA$.

Figure 2 illustrated PDOS of $\mathrm{La}_{\mathrm{x}} \mathrm{Nd}_{8-\mathrm{x}} \mathrm{B}_{6}(\mathrm{x}=0,1,7,8)$. As explicated in Figure 2(a) and Figure 2(c) PDOS curves. La d-electron bands show typical conductive behavior as they pass fermi energy. The lowermost conduction bands (CBs) consisted of B s and the uppermost valence bands (VBs) have consisted of $\mathrm{B}$ p are indicated in Figure 2(b). La d-electron band passing Fermi energies are shown in Figure 2(c). The calculation converged with great intensity to a metallic ground state at the $\mathrm{E}_{\mathrm{F}}$, at the Fermi level, as shown in the figure. The zone near $\mathrm{E}_{\mathrm{F}}$ is contributed mostly by La d states as explicit in Figure $2(\mathrm{~b})$ and Figure 2 (c). Besides that, $\mathrm{E}_{\mathrm{F}}$ is contributed generally by $\mathrm{Nd} d$ states as shown in Figure 2 (e) and Figure 2(g). This is obvious that the energy division of the La d states and $\mathrm{Nd} d$ states additives look alike to B $2 \mathrm{p}$ additives, which is a signature of hybridization between La d-Nd d - B 2p states.

Figure 3 shows the charge density of $\mathrm{LaB}_{6}, \mathrm{La}_{7} \mathrm{Nd}_{1} \mathrm{~B}_{6}, \mathrm{La}_{1} \mathrm{Nd}_{7} \mathrm{~B}_{6}$ and $\mathrm{NdB}_{6}$. Light and dark colors show high and low-intensity zones respectively. Dark and light colours indicate low and high-density regions, respectively. $\mathrm{La}_{1} \mathrm{Nd}_{7} \mathrm{~B}_{6}$ has a 
low-density region and $\mathrm{LaB}_{6}$ has a high-density region. There are six boron atoms on the plane. The center of the figure was seen the strong $B-B$ bonds. The $\mathrm{LaB}_{6}$ midpoint has strong charge density peaks. $\mathrm{La}_{1} \mathrm{Nd}_{7} \mathrm{~B}_{6}$ has weak peaks.

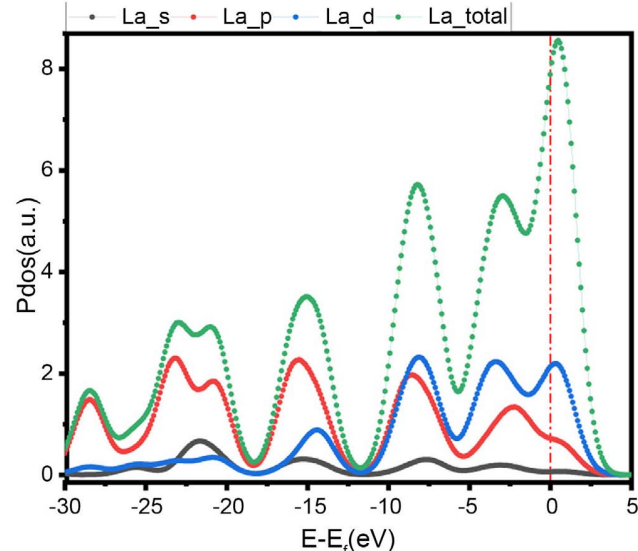

(a) $\mathrm{La}$ of $\mathrm{LaB}_{6}$

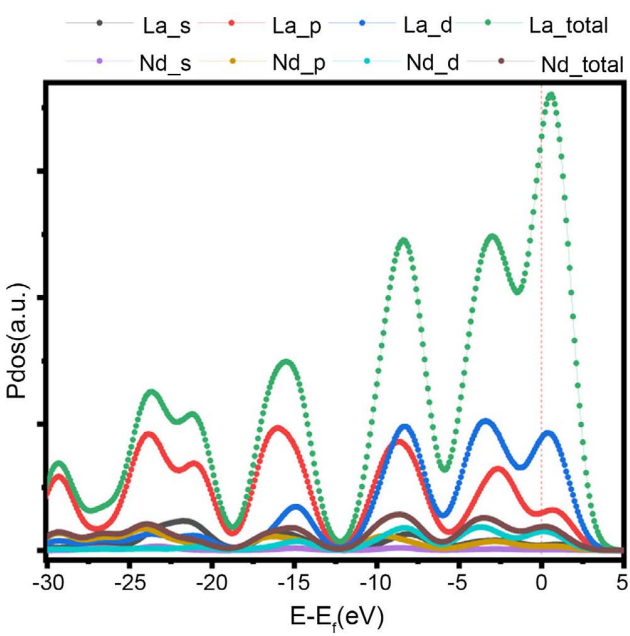

(c) $\mathrm{La}$ and $\mathrm{Nd}$ of $\mathrm{La}_{7} \mathrm{Nd}_{1} \mathrm{~B}_{6}$

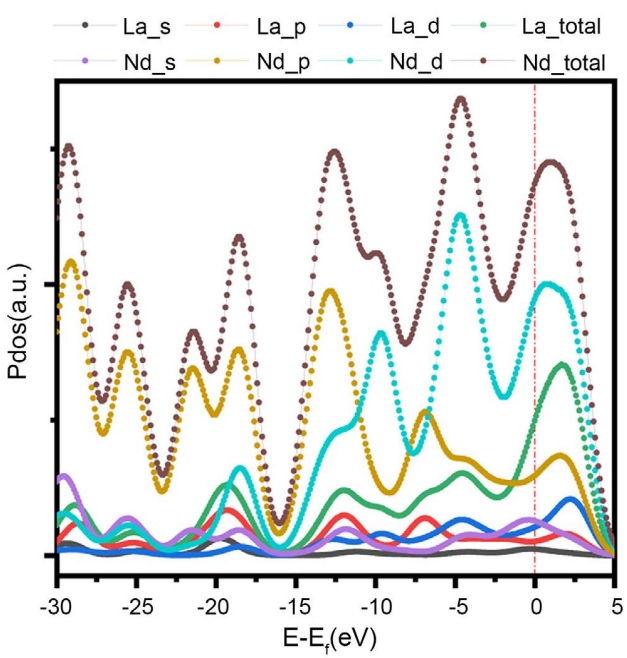

(e) $\mathrm{La}$ and $\mathrm{Nd}$ of $\mathrm{La}_{1} \mathrm{Nd}_{7} \mathrm{~B}_{6}$

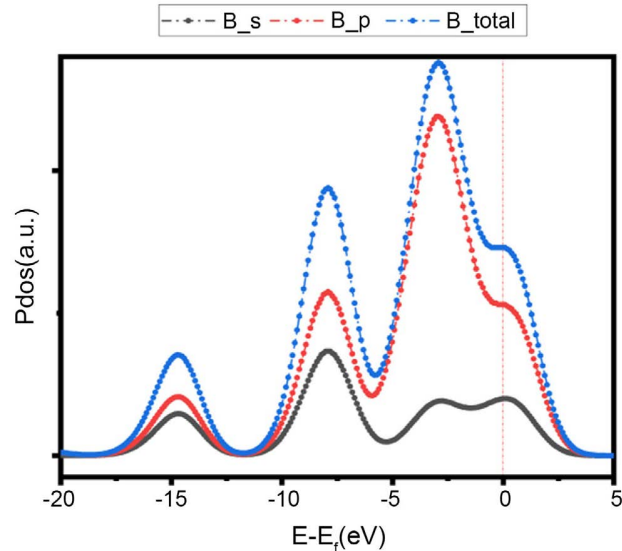

(b) $\mathrm{B}$ of $\mathrm{LaB}_{6}$

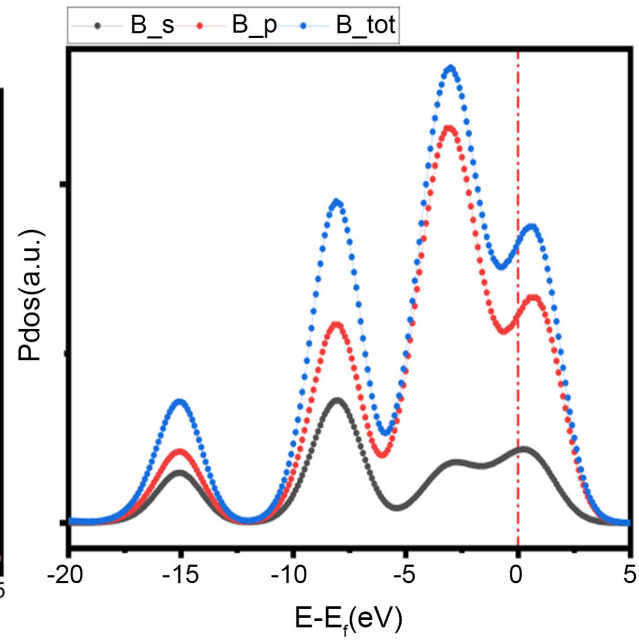

(d) $\mathrm{B}$ of $\mathrm{La}_{7} \mathrm{Nd}_{1} \mathrm{~B}_{6}$

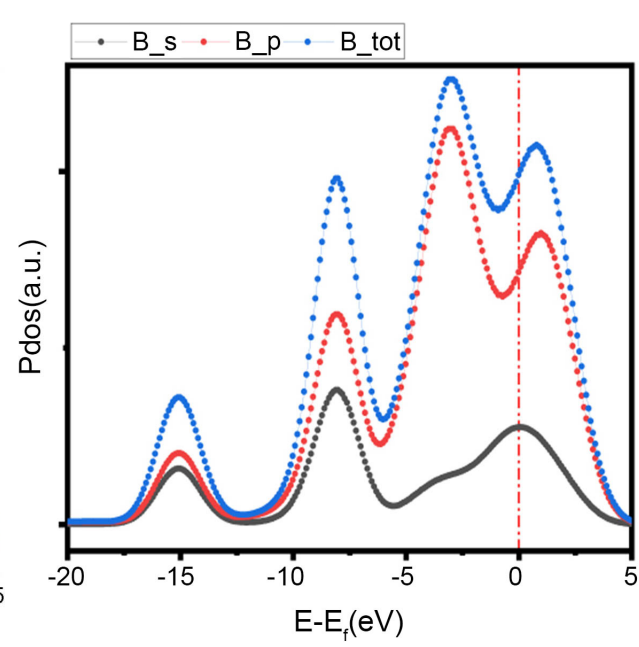

(f) $\mathrm{B}$ of $\mathrm{La}_{1} \mathrm{Nd}_{7} \mathrm{~B}_{6}$ 


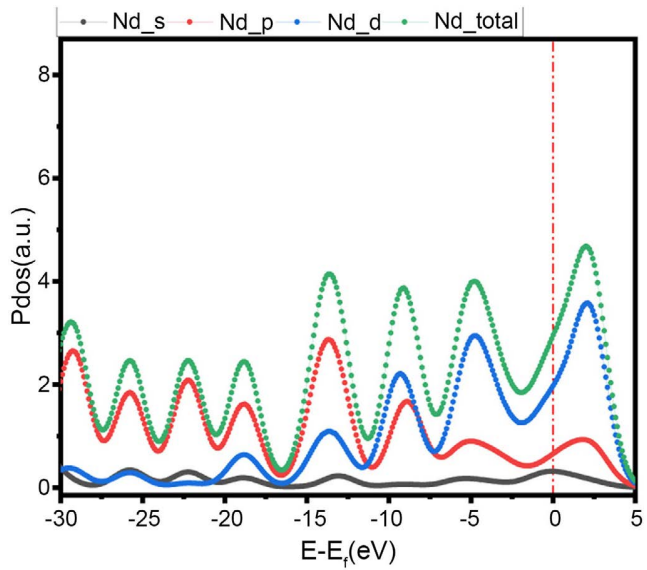

(g) $\mathrm{Nd}$ of $\mathrm{NdB}_{6}$

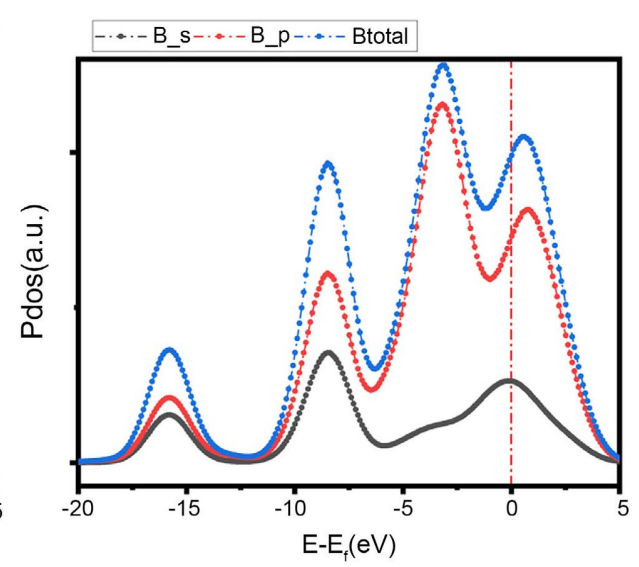

(h) B of $\mathrm{NdB}_{6}$

Figure 2. The partial density of states (PDOS) of (a) $\mathrm{LaB}_{6}$ (b) $\mathrm{B}$ of $\mathrm{LaB}_{6}$ (c) $\mathrm{La}_{7} \mathrm{Nd}_{1} \mathrm{~B}_{6}$ (d) $\mathrm{B}$ of $\mathrm{La}_{7} \mathrm{Nd}_{1} \mathrm{~B}_{6}(\mathrm{e}) \mathrm{La}_{1} \mathrm{Nd}_{7} \mathrm{~B}_{6}$ (f) $\mathrm{B}$ of $\mathrm{La}_{1} \mathrm{Nd}_{7} \mathrm{~B}_{6}$ (g) $\mathrm{NdB}_{6}$ (h) B of $\mathrm{NdB}_{6}$.
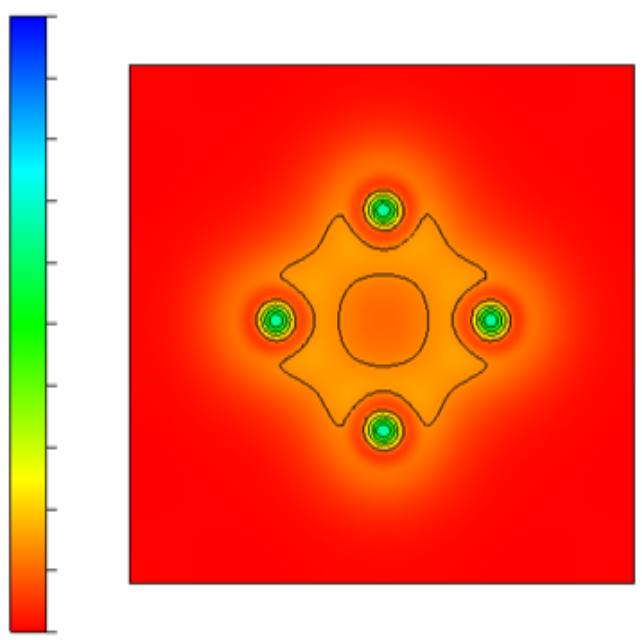

(a) $\mathrm{LaB}_{6}$
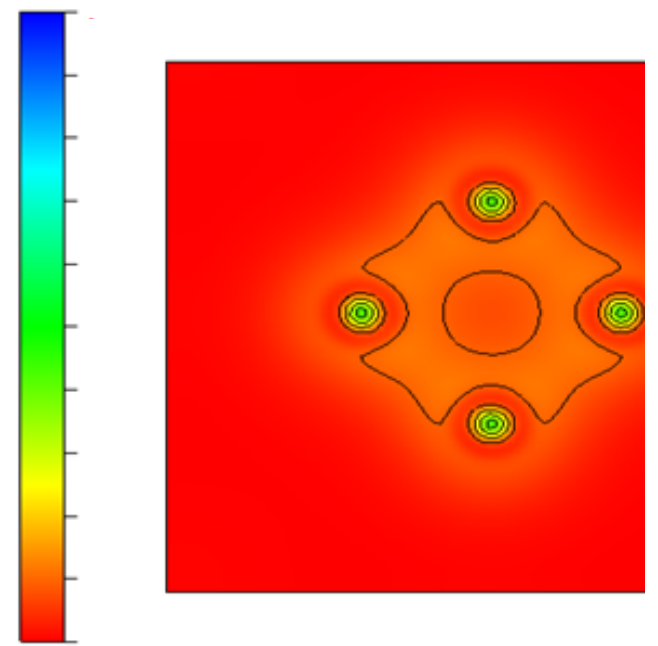

(c) $\mathrm{La}_{1} \mathrm{Nd}_{7} \mathrm{~B}_{6}$
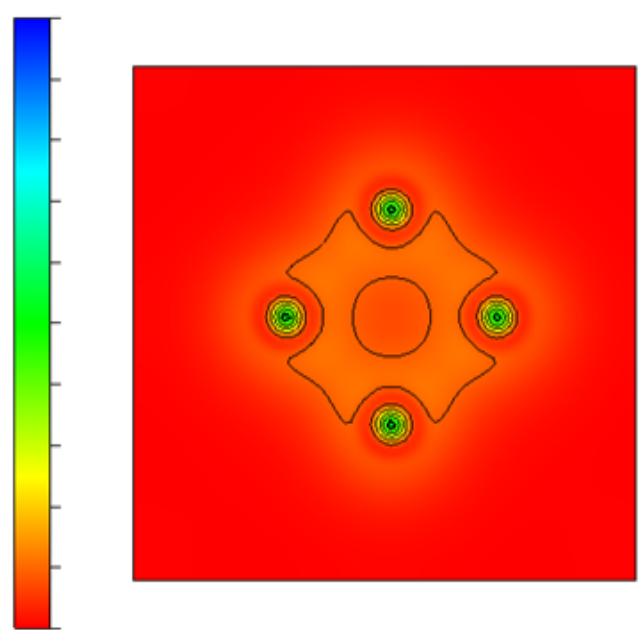

(b) $\mathrm{La}_{7} \mathrm{Nd}_{1} \mathrm{~B}_{6}$
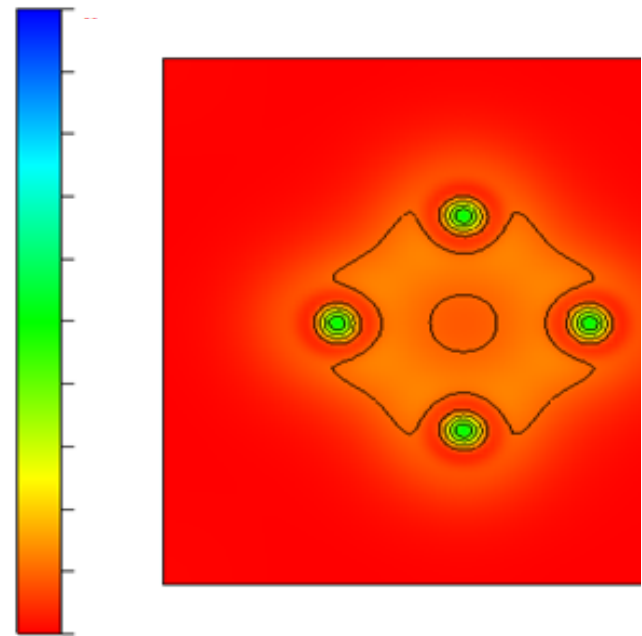

(d) $\mathrm{NdB}_{6}$

Figure 3. The charge density of (a) $\mathrm{LaB}_{6}$ (b) $\mathrm{La}_{7} \mathrm{Nd}_{1} \mathrm{~B}_{6}$ (c) $\mathrm{La}_{1} \mathrm{Nd}_{7} \mathrm{~B}_{6}$ (d) $\mathrm{NdB}_{6}$. 


\section{Conclusion}

We comprehensively studied the mechanical and electronic properties of $\mathrm{LaB}_{6}$, $\mathrm{NdB}_{6}, \mathrm{Nd}$-doped $\mathrm{LaB}_{6}$ and La-doped $\mathrm{NdB}_{6}$ using the density functional theory. The lattice constant of $\mathrm{LaB}_{6}$ was lower than that of $\mathrm{Nd}$-doped $\mathrm{LaB}_{6}$. In addition, La doping increased the lattice constant of La-doped $\mathrm{NdB}_{6}$. We calculated the PDOS of $\mathrm{LaB}_{6}$, B for $\mathrm{LaB}_{6}, \mathrm{La}_{7} \mathrm{Nd}_{1} \mathrm{~B}_{6}$, B for $\mathrm{La}_{7} \mathrm{Nd}_{1} \mathrm{~B}_{6}, \mathrm{La}_{1} \mathrm{Nd}_{7} \mathrm{~B}_{6}$, B of $\mathrm{La}_{1} \mathrm{Nd}_{7} \mathrm{~B}_{6}$, $\mathrm{NdB}_{6}$, and $\mathrm{B}$ of $\mathrm{NdB}_{6}$. We found that the La d-electron bands pass the Fermi energy as shown in Figure 2(c). The light color in the charge density indicates that $\mathrm{LaB}_{6}$ has a high-density region. Similarly, dark color in the charge density shows that $\mathrm{La}_{1} \mathrm{Nd}_{7} \mathrm{~B}_{6}$ has a low-density region.

\section{Conflicts of Interest}

The author declares no conflicts of interest regarding the publication of this paper.

\section{References}

[1] Zeng, X., Ye, Y., Zou, S., Gou, Q., Wen, Y. and Ou, P. (2017) First-Principles Study of the Nonlinear Elasticity of Rare-Earth Hexaborides REB6 $(\mathrm{RE}=\mathrm{La}, \mathrm{Ce})$. Crystals, 7, 320. https://doi.org/10.3390/cryst7110320

[2] Ji, X.H., Zhang, Q.Y., Xu, J.Q. and Zhao, Y.M. (2011) Rare-Earth Hexaborides Nanostructures: Recent Advances in Materials, Characterization and İnvestigations of Physical Properties. Progress in Solid State Chemistry, 39, 51-69. https://doi.org/10.1016/j.progsolidstchem.2011.04.001

[3] Liu, H., Zhang, X., Xiao, Y. and Zhang, J. (2018) The Electronic Structures and Work Functions of (100) Surface of Typical Binary and Doped REB6 Single Crystals. Applied Surface Science, 434, 613-619. https://doi.org/10.1016/j.apsusc.2017.10.233

[4] Liu, H., Zhang, X., Ning, S., Xiao, Y. and Zhang, J. (2017) The Electronic Structure and Work Functions of Single Crystal $\mathrm{LaB}_{6}$ Typical Crystal Surfaces. Vacuum, 143 245-250. https://doi.org/10.1016/j.vacuum.2017.06.029

[5] Uijttewaal, M.A., De Wijs, G.A. and De Groot, R.A. (2006) Ab Initio and Work Function and Surface Energy Anisotropy of $\mathrm{LaB}_{6}$. The Journal of Physical Chemistry $B, 110,18459-18465$. https://doi.org/10.1021/jp063347i

[6] Yu, Y., Wang, S., Li, W., Chen, H. and Chen, Z. (2018) Synthesis of SingleCrystalline Lanthanum Hexaboride Nanocubes by a Low Temperature Molten Salt Method. Materials Chemistry and Physics, 207, 325-329. https://doi.org/10.1016/j.matchemphys.2017.12.081

[7] Zhang, M., et al. (2008) A Low-Temperature Route for the Synthesis of Nanocrystalline $\mathrm{LaB}_{6}$. Journal of Solid State Chemistry, 181, 294-297. https://doi.org/10.1016/j.jssc.2007.12.011

[8] Yu, Y., Wang, S., Li, W. and Chen, Z. (2018) Low Temperature Synthesis of LaB Nanoparticles by a Molten Salt Route. Powder Technology, 323, 203-207. https://doi.org/10.1016/j.powtec.2017.09.049

[9] Dou, Z.-H., et al. (2015) A New Method of Preparing NdB6 Ultra-Fine Powders. Rare Metals, 1-7. https://doi.org/10.1007/s12598-015-0596-0

[10] Yadav, K.K., Sreekanth, M., Ghosh, S., Ganguli, A.K. and Jha, M. (2020) Excellent 
Field Emission from Ultrafine Vertically Aligned Nanorods of NdB6 on Silicon Substrate. Applied Surface Science, 526, Article ID: 146652.

https://doi.org/10.1016/j.apsusc.2020.146652

[11] Wang, G., Brewer, J.R., Chan, J.Y., Diercks, D.R. and Cheung, C.L. (2009) Morphological Evolution of Neodymium Boride Nanostructure Growth by Chemical Vapor Deposition. The Journal of Physical Chemistry C, 113, 10446-10451. https://doi.org/10.1021/jp901717h

[12] Ali, N. and Woods, S.B. (1983) Low Temperature Thermoelectric Power of LaB 6 , PrB6 and NdB6. Solid State Communications, 46, 33-35. https://doi.org/10.1016/0038-1098(83)90024-8

[13] Ding, Q., Zhao, Y., Xu, J. and Zou, C. (2007) Large-Scale Synthesis of Neodymium Hexaboride Nanowires by Self-Catalyst. Solid State Communications, 141, 53-56. https://doi.org/10.1016/j.ssc.2006.10.001

[14] Xu, J., et al. (2013) Excellent Field-Emission Performances of Neodymium Hexaboride (NdB6) Nanoneedles with Ultra-Low Work Functions. Advanced Functional Materials, 23, 5038-5048. https://doi.org/10.1002/adfm201301980

[15] Tsuji, S., Endo, T., Kobayashi, S., Yoshino, Y., Sera, M. and Iga, F. (2002) Rapid Suppression of the Metamagnetic Transition for H 111 in NdB6 by La Doping. Journal of the Physical Society of Japan, 71, 2994-3002. https://doi.org/10.1143/JPSJ.71.2994

[16] Liang, C.-L., Zhang, X., Zhang, J.-X., Zhang, F.-X. and Wang, Y. (2015) Preparation and Property of $\mathrm{La}_{1-\mathrm{x}} \mathrm{Nd}_{\mathrm{x}} \mathrm{B}_{6}$ Cathode Material. Journal of Inorganic Materials, 30, 363-368. https://doi.org/10.15541/jim20140471

[17] Li, Q., et al. (2015) Single-Crystalline $\mathrm{La}_{x} \mathrm{Nd}_{1-\mathrm{x}} \mathrm{B}_{6}$ Nanowires: Synthesis, Characterization and Field Emission Performance. Journal of Materials Chemistry C, 3, 7476-7482. https://doi.org/10.1039/C5TC00804B

[18] Giannozzi, P., et al. (2017) Advanced Capabilities for Materials Modelling with Quantum ESPRESSO. Journal of Physics. Condensed Matter, 29, Article ID: 465901. https://doi.org/10.1088/1361-648X/aa8f79

[19] Hobbs, D., Kresse, G. and Hafner, J. (2000) Fully Unconstrained Noncollinear Magnetism within the Projector Augmented-Wave Method. Physical Review B, 62, 11556-11570. https://doi.org/10.1103/PhysRevB.62.11556

[20] Hacker Jr., H. and Lin, M.S. (1968) Magnetic Susceptibility of Neodymium Hexaboride. Solid State Communications, 6, 379-381. https://doi.org/10.1016/0038-1098(68)90161-0

[21] Tekoğlu, E., Ağaoğulları, D., Yürektürk, Y., Bulut, B. and Öveçoğlu, M.L. (2018) Characterization of $\mathrm{LaB}_{6}$ Particulate-Reinforced Eutectic Al-12.6 wt\% Si Composites Fabricated via Mechanical Alloying and Spark Plasma Sintering. Powder Technology, 340, 473-483. https://doi.org/10.1016/j.powtec.2018.09.055

[22] Xiao, Y., Zhang, X., Li, R., Liu, H., Zhou, N. and Zhang, J. (2021) Single-Crystal $\mathrm{LaB}_{6}$ Field Emission Array is Rapidly Fabricated by Ultraviolet Femtosecond Laser and İts Field Electronic Structure Characteristics. Vacuum, 184, Article ID: 109987. https://doi.org/10.1016/j.vacuum.2020.109987

[23] Soloviova, T.O., Karasevska, O.P., Vleugels, J. and Loboda, P.I. (2021) Thermal Dependent Properties of $\mathrm{LaB}_{6}-\mathrm{MeB}_{2}$ Eutectic Composites. Ceramics International, 47, 17667-17677. https://doi.org/10.1016/j.ceramint.2021.03.086

[24] Ivashchenko, V.I., Turchi, P.E.A., Shevchenko, V.I., Medukh, N.R., Leszczynski, J. and Gorb, L. (2018) Electronic, Thermodynamics and Mechanical Properties of $\mathrm{LaB}_{6}$ from First-Principles. Physica B: Condensed Matter, 531, 216-222. 
https://doi.org/10.1016/j.physb.2017.12.044

[25] Otani, S., Honma, S., Yajima, Y. and Ishizawa, Y. (1993) Preparation of LaB 6 Single Crystals from a Boron-Rich Molten Zone by the Floating Zone Method. Journal of Crystal Growth, 126, 466-470. https://doi.org/10.1016/0022-0248(93)90052-X

[26] Bai, L., Ma, N. and Liu, F. (2009) Structure and Chemical Bond Characteristics of LaB. Physica B: Condensed Matter, 404, 4086-4089. https://doi.org/10.1016/j.physb.2009.07.189

[27] Ghimire, M.P., Rai, D.P., Patra, P.K., Mohanty, A.K. and Thapa, R.K. (2012) Study of Bulk Modulus, Volume, Energy, Lattice Parameters and Magnetic Moments in Rare Earth Hexaborides Using Density Functional Theory. Journal of Physics. Conference Series, 377, 12084. https://doi.org/10.1088/1742-6596/377/1/012084

[28] Chen, C.-H., Aizawa, T., Iyi, N., Sato, A. and Otani, S. (2004) Structural Refinement and Thermal Expansion of Hexaborides. Journal of Alloys and Compounds, 366, L6-L8. https://doi.org/10.1016/S0925-8388(03)00735-7

[29] Simsek, T., Avar, B., Ozcan, S. and Kalkan, B. (2019) Nano-Sized Neodymium Hexaboride: Room Temperature Mechanochemical Synthesis. Physica B: Condensed Matter, 570, 217-223. https://doi.org/10.1016/j.physb.2019.06.047

[30] Han, W., Zhang, H., Chen, J., Zhao, Y., Fan, Q. and Li, Q. (2015) Synthesis of Single-Crystalline NdB 6 Submicroawls via a Simple Flux-Controlled Self-Catalyzed Method. RSC Advances, 5, 12605-12612. https://doi.org/10.1039/C4RA13129K

[31] Blomberg, M.K., Merisalo, M.J., Korsukova, M.M. and Gurin, V.N. (1995) Single-Crystal X-Ray Diffraction Study of NdB6, EuB6 and YbB6. Journal of Alloys and Compounds, 217, 123-127. https://doi.org/10.1016/0925-8388(94)01313-7

[32] Fan, Q.H., et al. (2013) Field Emission from One-Dimensional Single-Crystalline $\mathrm{NdB}_{6}$ Nanowires. Journal of Rare Earths, 31, 145-148. https://doi.org/10.1016/S1002-0721(12)60248-8

[33] Xiao, L., et al. (2012) Origins of High Visible Light Transparency and Solar HeatShielding Performance in $\mathrm{LaB}_{6}$. Applied Physics Letters, 101, 41913. https://doi.org/10.1063/1.4733386

[34] Hasan, M., Sugo, H. and Kisi, E. (2013) Low Temperature Carbothermal and Boron Carbide Reduction Synthesis of LaB6. Journal of Alloys and Compounds, 578, 176-182. https://doi.org/10.1016/j.jallcom.2013.05.008

[35] Sandeep, M.P., Rai, D.P., Patra, P.K., Mohanty, A.K. and Thapa, R.K. (2012) Study of Bulk Modulus, Volume, Energy, Lattice Parameters and Magnetic Moments in Rare Earth Hexaborides Using Density Functional Theory. Journal of Physics. Conference Series, 377, 12084. https://doi.org/10.1088/1742-6596/377/1/012084

[36] Hasegawa, A. and Yanase, A. (1977) Energy Bandstructure and Fermi Surface of $\mathrm{LaB}_{6}$ by a Self-Consistent APW Method. Journal of Physics F: Metal Physics, 7, 1245-1260. https://doi.org/10.1088/0305-4608/7/7/023

[37] Mackinnon, I., Alarco, J. and Talbot, P. (2013) Metal Hexaborides with Sc, Ti or Mn. Modeling and Numerical Simulation of Material Science, 3, 158-169. https://doi.org/10.4236/mnsms.2013.34023

[38] Bao, L.-H., Zhang, J.-X., Zhang, N., Li, X.-N. and Zhou, S.-L. (2012) In Situ $\left(\mathrm{La}_{x} \mathrm{Gd}_{1-x}\right) \mathrm{B}_{6}$ Cathode Materials Prepared by the Spark Plasma Sintering Technique. Physica Scripta, 85, 35710. https://doi.org/10.1088/0031-8949/85/03/035710

[39] Chao, L., Bao, L., Shi, J., Wei, W., Tegus, O. and Zhang, Z. (2015) The Effect of Sm-Doping on Optical Properties of $\mathrm{LaB}_{6}$ Nanoparticles. Journal of Alloys and Compounds, 622, 618-621. https://doi.org/10.1016/j.jallcom.2014.10.141 
[40] Hasan, M.M., Cuskelly, D., Sugo, H. and Kisi, E.H. (2015) Low Temperature Synthesis of Low Thermionic Work Function $\left(\mathrm{La}_{x} \mathrm{Ba}_{1-x}\right) \mathrm{B}_{6}$. Journal of Alloys and Compounds, 636, 67-72. https://doi.org/10.1016/j.jallcom.2015.02.105

[41] Luo, K., et al. (2016) Crystal Structures and Mechanical Properties of M (Mg, Sr, Ba, La) $\mathrm{xCa}_{1-x} \mathrm{~B}_{6}$ Solid Solution: A First Principles Study. Ceramics International, 42, 6632-6639. https://doi.org/10.1016/j.ceramint.2016.01.002

[42] Qin, P., Xu, C. and Chen, D. (2012) Electronic and Optical Properties of $\mathrm{RB}_{6}(\mathrm{R}=$ La, Nd): A Computer Aided Design. Advanced Materials Research, 571, 239-242. https://doi.org/10.4028/www.scientific.net/AMR.571.239 